Published in final edited form as:

Int J Technoethics. 2015 ; 6(2): 47-59. doi:10.4018/IJT.2015070104.

\title{
Globalization and Global Health
}

\section{Florencia Luna}

FLASCO, Buenos Aires, Argentina

\begin{abstract}
Globalization shrinks the world. The world watches on television people dying of hunger or in extreme poverty conditions. Every year, 8 million children die before they reach the age of 5 from preventable diseases. "Exotic illnesses" cease to be so exotic, they can cross borders easily. Ebola, originally an African worry, in 2014 was an international threat. The revolution in information technologies enables us witness the emergence of transnational epistemic communities exhibiting, measuring and explaining health and disease. Presently, the authors are more aware than ever of the health problems of people from far away countries, which decades ago were unknown and distant. The transparency and availability of this information exhibits, in a quasi-obscene way, an unacceptable world. A world that is willing to rescue banks and ignores the worst off - those people whose unlucky birth seals a never ending cycle of misery with almost no possibility of breaking it. This paper address the situation just described by asking: Are these new empiric circumstances reflected in the authors' moral understanding of the issues? How should the world think of global health and their obligations towards people living in deprivation? How can the new empiric possibilities the global world offers be related to the implementation of such obligations? What are some of the challenges to the translation of new obligations to the present world? In addressing these questions, the paper argues that if the world seriously wants to address the obligations towards those in need, even if they are far away from the places they may need to work not only with ideal proposals such as the "new obligations" pointed by Singer and Pogge, but also with different transitional theories and non-ideal strategies in order to solve some of the big challenges the real world impose to theories.
\end{abstract}

Copying or distributing in print or electronic forms without written permission of IGI Global is prohibited.

Florencia Luna, holds an MA from the University of Columbia (USA) and a PhD in Philosophy from the University of Buenos Aires. She directs the Bioethics Program at FLACSO (Latin American University of Social Sciences-Argentina) and at the University of Buenos Aires (UBA) and is an Independent Researcher at CONICET (National Scientific and Technological Research Council) since 2000. She has been a Board Member of the International Association of Bioethics (IAB) (1999-2007), President of the IAB (20032005), temporary advisor of World Health Organization (WHO) and the Council for International Organizations of Medical Sciences (CIOMS). She was a member of the Steering Committee of CIOMS working on the International Ethical Guidelines for Biomedical Research Involving Human Subjects (2002). In addition to directing a research program on bioethics at FLACSO, she was co-director with Ruth Macklin to train persons in ethics and research (2000-2006) and Director of a Training grant (2006-2011) of the Fogarty International Center (National Institutes of Health-NIH (US)). She has won the Guggenheim Foundation Fellow (2006) and has been awarded the Konnex Prize: Honor Diploma in Ethics in 2006, in recognition of important figures in Humanities in Argentina during the last decade (1996-2006). She is a visiting researcher at the Brocher Foundation (Switzerland) 2011, and editor of Perspectivas bioeticas since 1996 (the first Argentinean journal wholly devoted to bioethics). Her publications include Bioethics and Vulnerability: A Latin American View (RODOPY, Amsterdam-US, 2006), several co-authored books and a variety of articles in journals and books. Presently she is working on issues related to research in developing countries, international research ethics, gender, cord blood banks, and genetics and ethics.

20"The mínimum amount that firms should devote to rescue is the largest sum of their most recent year's investment in social initiatives, their fime-year trend, their industry's average or the national average." Ibid. p. 185.

${ }^{21}$ This is not undoable. For example, Coca Cola has delivered AIDS testing kits to hospitals in Nigeria, billboards for awareness campaigns in Kenya. Dunfee (2006) p. 189. 


\section{Keywords}

Globalization; Ideal; Illness; Poverty; Strategy Sick; Transitional; Vulnerable

\section{INTRODUCTION}

Globalization shrinks the world. We watch on television people dying of hunger or in extreme poverty conditions. Every year, 8 million children die before they reach the age of 5 from preventable diseases. "Exotic illnesses" cease to be so exotic, they can cross borders easily. Ebola, originally an African worry, in 2014 was an international threat. The revolution in information technologies enables us to witness the emergence of transnational epistemic communities exhibiting, measuring and explaining health and disease. Presently, we are more aware than ever of the health problems of people from far away countries, which decades ago were unknown and distant. The transparency and availability of this information exhibits, in a quasi-obscene way, an unacceptable world. A world that is willing to rescue banks and ignores the worst off - those people whose unlucky birth seals a never ending cycle of misery with almost no possibility of breaking it.

This unfair and unequal picture of the world is a background we cannot deny. However globalization also offers another face: helping each other is easier than it was a century ago, for example, just a click in our laptop or tablet and we can send money to the other side of the world. In addition, there is an international architecture of human rights and international organizations as well as several non-governmental organizations (NGOs) that function globally and can make a difference for these populations. Are these new circumstances reflected in our moral understanding of the issues? How should we think of global health and our obligations towards people living in deprivation? How can the new empiric possibilities the global world offers be related to the implementation of such obligations? What are some of the challenges to the translation of new obligations to the present world?

In this paper I will work with the individual and institutional models represented by Peter Singer and Thomas Pogge. These philosophers come from different conceptual backgrounds, but they are both concerned with the global situation and poverty. They redefine our obligations to the global poor and its health. I will only sketch some of their main arguments because in the rest of the article. I will explore how to face a major challenge which is the difficulty of complying with those "new" obligations. I will use nonideal strategies as a possible resource.

\section{TRADITIONAL, INDIVIDUAL AND INSTITUTIONAL ARGUMENTS}

As noted in the introduction, one problem is posed by the situation of poor people that die from preventable diseases and lack of access to health care, as children or women that die because of unsafe conditions at childbirth. And another situation is the one presented, by the risks entailed by certain transmissible illnesses (Ebola, swine fever, TB). They affect poor people but can also be a threat for other populations. 
Different arguments can be given for one or the other case. Regarding poverty and global health the traditional view considers that alleviating poverty belongs to the realm of beneficence, to our feelings and our heart. It is an act of charity. Poor people are in an unfortunate situation but this is not unjust. They merit our sympathy and these nice feelings lead to charity or beneficence. The assumption is that we are not obliged to reduce extreme poverty. Thus, if there is a moral problem here it is our lack of generosity but not the violation of any moral principle or moral duty.

Regarding the second situation, globalization instead may lead to another argument besides charity. We should help these populations in order to prevent these illnesses from impacting other parts of the world (that is, can impact us). The rationale behind it is self-interest. We want to avoid that our countries "import" such threats. Not only self-interest is not even a moral principle-it is the rationale for actions done by convenience-; but also if we follow this argument we will be committed to address only certain illness (mainly those that are transmissible and can cross borders) and not necessarily the most important threats to poor populations.

This second argument does not actually address global health; on the other hand, just appealing to charity is completely subjective. As previously said it depends on our good feelings, there are no moral requirements. The charitable may be praised but those who are not charitable are not condemned. Are there other ways of addressing the problem of global health? Can we think our obligations in this "shrinking world" where we are all interconnected with more stringent moral categories?

Certainly. There are other positions that provide another perspective to the problem. We can think of new obligations from at least two perspectives: an individual and an institutional one. From a consequencialist and individual perspective Peter Singer was one of the first philosophers to point out the shame of global poverty and our obligations towards the poor. In 1972 he wrote a remarkable article "Famine, affluence and morality" which challenged the established ethics based on beneficence as the moral value justifying helping the socalled distant and absolute poor. Singer defied the rationale of helping the needy as a mere act of charity, an imperfect duty, depending on our good will and feelings. In this and other writings Singer asks whether we have an obligation to help those whose lifes are in danger; for example, those who may suffer a premature and preventable death. For him, suffering and death from lack of food, shelter and medical care are bad (Singer, 1972 p. 586). Thus suffering has a negative moral value. In "Famine, Affluence and Morality" he provides a principle: "If it is in our power to prevent something bad from happening, without thereby sacrificing anything of comparable moral importance, we ought, morally, to do it" (Singer, 1972 p. 586). Helping others is not charity, a supererogatory act, praiseworthy if one does it, but not unfair or unjust to omit. It is something one has an obligation to do. Thus Singer moves out from mere beneficence and defends an obligation to help, a positive duty. $\mathrm{He}$ argues for redrawing the distinction between the respective scope of duty and charity.

Interestingly for our present ideas about globalization, when presenting this 1972 principle, Singer will point out that it does not matter if the people whom we can help are near or far from us. Proximity is not relevant. He acknowledges that there might be a psychological 
difference but this is not a moral one. We might have a predisposition to help a person that lives in our neighborhood or city than another from a far-away country. But this does not imply that we have moral obligations towards the first one and not the latter. Our moral obligations are to all of them. And we should help first the person that is in most need, not the one that is near us or that we happen to know. Moreover, if we argue that we can be more effective with people that are nearer, Singer will challenge this effectiveness by pointing to globalization: the development of the world into a "global village" where there is instant communication and swift transportation that brings almost as effective help (Singer, $1972 \mathrm{p}$. 587). So given this, we cannot discriminate on geographical grounds.

To make his reasoning more intuitive, Singer offers an application of his principle. He explains this positive duty with an analogy: we should act in the same way as a bystander should act if he sees a child drowning in a shallow pond. The bystander has an obligation to rescue the child (Singer, 1972 p. 586), even if this means getting his clothes muddy. Undoubtedly Singer challenges the traditional thinking... He represents a first step in thinking our obligations and relations towards the distant poor in a more connected way. Distance does not have moral relevance and our obligations do not fit the traditional understanding.

An even stronger argument is the one provided by Thomas Pogge. He is not just thinking in positive duties, as Singer argues, but in stronger duties: negative duties. His argument is based on compensatory health-related moral obligations due to harm and the need to compensate those wronged. He points out that the existing radical inequality is deeply tainted by how it accumulated through the historical process that was deeply pervaded by enslavement, colonialism and even genocide. For Pogge we are not "innocent" bystanders (as Singer's example suggests), we benefit from massive grievous wrongs done in the past as well as from the current economic order (Pogge, 2001). One of his arguments is that the life of the world's rich and poor are inextricably linked because of harmful state-to-state actions. Pogge will argue that currently existing transnational institutions secure high standards of living for the affluent and reinforce the deprivation of many of the global poor. The causes of the current persistence of severe poverty are not exclusively domestic to the countries in which it occurs. For Pogge the asymmetries inherent in the current global economic regime are well documented. They allow rich countries to favor their own companies through tariffs, quotas, anti-dumping duties, export credits and huge subsidies, among others (Pogge, 2002; Pogge 2008). Therefore compensatory justice implies there are moral obligations beyond borders. We leave here the realm of charity and beneficence, and even the positive duties that Singer argues for to enter a justice based proposal. For Pogge, poor conditions of health are caused directly or indirectly by the actions of powerful global actors. The strong concept involved is the one of harm and this implies we have a responsibility for such harms. He will also introduce the concept of human rights. Against the presumption that human rights entail only negative duties, Pogge will argue human rights do impose positive duties, even internationally. And he will defend that there are human-rights-based obligations. In this analysis we can already witness the force of globalization.

Contrary positions ${ }^{1}$ criticize Pogge's reasoning, arguing that it is impossible to quantify the actual harm done by the world economic order. Or disapprove of how to respond when 
health needs occur as a result of forces unrelated to the global world order, for example, a Tsunami or even terrible economic mismanagement. ${ }^{2}$ Even if we can recognize problems and criticisms, undoubtedly Pogge presents new arguments for new obligations with a forceful commitment to the global poor and their health.

\section{NON-IDEAL APPROACHES}

Can we then stop here and feel satisfied by what we have reached so far? We have at least two strong positions redefining moral boundaries and establishing new obligations. But, what happens with these arguments and proposals when we go back to the actual world? An issue worth considering is that ethical and political theories designing institutions and attributing responsibilities assume an ideal world where people comply with their responsibilities and ethical requirements. But-as we will show-this is not the case. Even if we feel interconnected it is not the same kind of nearness as the one we have to our neighbors or fellow citizens and non-compliance is an obstacle that a global perspective should tackle.

In an imperfect world with extreme conditions and scarcity, where ideal responsible agents do not comply, and where institutions are unjust or unfair, we should think if a non-ideal strategy can play a role and how this can be. ${ }^{3}$ In what follows I want to show some of these challenges and explore different analyses.

This is a recently new domain in political philosophy (Hamlin \& Stemplowska 2012, Simmons 2010) and it is even newer for bioethics. In the past five years philosophers have begun working on the topic though some of the issues-as we will see-have been considered before. Still this is an area that deserves more work, as it may prove very relevant.

John Rawls was the first to introduce the distinction between ideal and non-ideal theories. ${ }^{4}$ Rawls refers to an ideal theory as a well-ordered institutional arrangement. ${ }^{5}$ Institutions are well ordered when they are both just and known to be just, and when individuals both accept and fully comply with the requirements these institutions impose on them. This suggests at least two rather different ways in which circumstances may fail to be ideal. On the one hand, individuals may not fully comply; on the other, background institutions may not be just. ${ }^{6}$ In what follows I will show that his proposal can be applied broadly and not only to fullfledged theories.

The first set of challenges considered noncompliance. When dealing with non-compliance Rawls explains that it comprises such topics as theory of punishment, doctrines of just war, and various way of approving unjust regimes. Later, it is Liam Murphy who thoroughly

\footnotetext{
${ }_{1}^{1}$ For example, M. Risse. See Lowry C and Shucklenk U., op.cit. p10.

2 Lowry C and Shucklenk U., op.cit. p10.

3 It can be argued whether ideal theories are applicable to more "normal" situations because in the real world, people do not generally comply with their obligations. Aside from this controversy it is clear that in very scarce resource settings where global health is not achieved, conditions are unmistakably far from ideal.

${ }^{4}$ John Rawls, Justice as Fairness: A Restatement, (Harvard University Press, Massachussets, 2001), p. 13.

5 The details of Rawls' interpretation go beyond this article. For a thorough analysis, see Simmons, 2010.

6I am following Sreenivasan, 2012 who argues for this distinction. Other philosophers, such as Murphy, 2000 or Feinberg, 1973 only consider partial compliance.
} 
examined partial-compliance challenges. ${ }^{7}$ Murphy analyzes the topic from a consequentialist perspective. He assumes that the ideal requirements of justice are to maximize everyone's total well-being. Under circumstances of partial compliance, total well-being remains at a suboptimal level. However, if a given individual can relieve some of the shortfall by contributing still more, then utilitarianism will require even more of that agent. Murphy claims that this is not fair. ${ }^{8} \mathrm{He}$ introduces a "compliance condition" which holds (roughly) that the cost to an agent of complying with the requirements of beneficence should not be higher under partial compliance than they are under full compliance. I will not enter in the details here. This position generated a debate and counter examples, but it showed a way out to this challenge.

The second set of challenges considered institutions. Transitional theory prescribes for the cases in which background institutions are not just. It specifies obligations when individuals have to bring just institutions into existence (background institutions may be unjust or may not exist). But how can we think this transitional theory? Though this was not developed by Rawls, in the following paragraph he provides several hints:

Non-ideal theory asks how this long-term goal might be achieved, or worked toward, usually in gradual steps. It looks for policies and courses of action that are morally permissible and politically possible as well as likely to be effective. So conceived non-ideal theory presupposes that the ideal theory is already on hand. For until the ideal is identified, at least in outline - and that is all we should expect - non-ideal theory lacks an objective, an aim, by reference to which its queries can be answered. ${ }^{9}$

A first suggestion we can infer from Rawls words is to work with a priority assumption. That is that the ideal theory is prior to the non-ideal theory and proceeds by reference to the content of an ideal theory. The ideal theory has a place: it can take the role of a target or aspiration. ${ }^{10}$ It may identify the objective at which to aim. This may apply not only to principles and institutions but to responsible agents. Again, we might think this broadly and apply it to different situations. Instead of only considering ideal responsible agents, a nonideal approach may be better. And the non-ideal approach can be justified until fairer and more feasible conditions for justice and ideal agents' actions are in effect, which lead us to the second idea we can infer.

A second suggestion, if we follow Rawls' ideas, is that non-ideal theories are gradual. They are constructed step by step, aiming for the ideal. A related feature is that they should be reconsidered and amended as circumstances change. Non-ideal theory' policies are not written in stone. In this sense there is a dynamic component included in this way of analyzing the situation. We can infer other intermediate policies and design a non-ideal theory. Ideal theory dictates the objective, and the non-ideal theory indicates the route to that

\footnotetext{
${ }^{7}$ Murphy L. Moral Demand in Nonideal Theory. New York: Oxford University Press, 2000. I will follow Sreenivasan's reconstruction; see Sreenivasan G. Nonideal Theory: A Taxonomy with illustration. In: Millum J, Emanuel E, eds. Global Justice and Bioethics. Oxford: Oxford University Press, 2012:153-177.

${ }^{8}$ Sreenivasan G. 2012, p. 168. Arneson R. Moral limits on the demands of beneficence?. In Chatterjee D. The Ethics of

Assistance:Morality and the Distant Needy. New York: University Press, 2004:33-58.

${ }^{9}$ Rawls J. The law of peoples. Cambridge (MA): Harvard University Press, 1999, pp. 89-90.

${ }^{10}$ There is also a debate regarding this interaction. See Zofia Stemplowska and Adam Swift, in press.
} 
objective. Finally they should be considered provisional or transitory, that is, when the situation and circumstances ameliorate non-ideal theories can be replaced or abandoned.

Thirdly, we can infer from Rawls that non-ideal theories require that specific policies and courses of actions must hold to four requisites: R.1. Morally permissible; R.2. Politically possible; R.3. Likely to be effective. Finally, we can complete this provisional scheme with a quite interesting remark provided by John Simmons. He infers another requirement - R.4. the most grievous injustices are to be dealt with before less severe ones. ${ }^{11}$

We have now new conceptual tools that may help us analyze the different problems we are going to face. In what follows I will explore if this strategy helps us think the challenges of non-compliance and our obligations to improve the health of distant others.

\section{THE INDIVIDUAL STRATEGY}

Let us reconsider the philosophers just presented. As we mentioned, Peter Singer targets individual responsibility: each affluent person has a moral obligation. Singer is mainly considering affluent people from developed countries, though he is not thinking of millionaires or the very wealthy people, but those persons like you and me that meet their basic needs and still have room for some luxuries (Singer 1972, p. 588). Singer speaks of the absolute rich people. For him they are those that after spending money in food, clothes, a place where to live, education... they still have money. They select their food because of their taste and not just to avoid being hungry, they buy unnecessary clothes to look "well dressed" or they can move to a house in a nice neighborhood and they still can go on holidays (Singer 1995, p. 275). ${ }^{12}$ In Singer's view, we ought to exercise our duty to assist the needy. The proposal at first sight is quite simple and, currently, it is quite easy. As mentioned, the world has changed and we can now use the Internet to help distant persons. It is also true that if each person is committed to global health or global poverty, more possibilities and help will become available. This would also mean a wider exercise of values such as solidarity through moral obligations. Moreover, if the suffering of others, even distant and unknown individuals, truly mattered and a moral obligation to help others was felt, the world would be better and fairer. Civil society and every individual can become fundamental actors in a profound change. However, no matter how easy and achievable this proposal may seem, we face non ideal conditions, for example, responsible agents do not always comply.

Because of this problem, Singer had to reduce the amount of money to be given. Hence if we go back to our presentation of Singer's proposal we can see it is incomplete because even in his first analysis Singer presents another principle less stringent. He passed from "If it is in our power to prevent something bad from happening, without thereby sacrificing anything of comparable moral importance, we ought, morally, to do it" (Singer 1972, p. 586). to "If it is in our power to prevent something very bad from happening, without thereby sacrificing anything morally significant, we ought, morally, to do it" (Singer 1972, p. 588). The stronger

${ }^{11}$ I am following Simmons reconstruction. See Simmons, 2010, pp. 18-19.

${ }^{12}$ Singer P, 1995, Ética Práctica (Segunda edición) Cambridge University Press, p 275 
version means reducing ourselves to the level of marginal utlility, that is until the point that if we give more we may cause as much suffering to us and our dependents as we could relief by our gift. However, it may be argued-as some philosophers have done - that giving to others until that point implies such a sacrifice that most of us who are not heroes or saints will not do it. The moderate version, instead, implies that a great change in our way of life is required but not the sacrifice the first principle involved. So in 1972, Singer considers the stronger principle as the morally correct one and the moderate principle as the second best option.

Years later in his book Practical Ethics, though he still defended the first principle, in the last section of the chapter he acknowledged some of criticisms and he decreased even more the levels of help. He asks to give $10 \%$ of the salary. He argued that $10 \%$ is more than a symbolic amount but it is not so much that we can be considered saints and it also reminds the tithe the church used to ask to help the poor. He argued this is the minimum we ought to give. Thus, here again demanding and noncompliance is a challenge and we can imagine how this last move is a huge concession for Singer. However in One world, a book published in 2002, he continued decreasing the percentage even more: he argues there for a $1 \%$. And, this is the percentage he still defends. ${ }^{13}$

Obviously Singer is aware of the change in the level of demand he has proposed. He acknowledges he is defending a weaker standard, even if he thinks and argues that he as well as other people that are persuaded of the correctness of these "new" obligations will endorse the first stronger principle. Singer is fully aware that only in this way he can convince ordinary people to act correctly. Probably the fact of being distant people contributes to noncompliance. In the 1972 article he considers Sidgwick and Urmson positions regarding this issue (Singer 1972, p. 589). ${ }^{14}$ As that section shows demandingness and what people are willing to comply with are not new philosophical topics.

This translation of the ideal strategy proposed by Singer to the real world implied major changes and alterations to the original proposal and we can argue that the end of the proposal-the $1 \%$ donation-seems a mockery when compared to the original principle. Can we think Singer's strategy as a concession to Murphy's compliance condition? In "Famine, Affluence and Morality" Singer seems to argue against this kind of compromise.

Instead of trying to interpret Singer's final proposal in these lines, a different answer might be to think Singer's weakening of standards as a transitional theory. When rejecting his critics Singer establishes a sort of double strategy one for "ordinary people" and another for "persuaded people" like him. I think a version of this idea is to propose it as a non-ideal strategy. Following this approach, we could think this first $1 \%$-as a gradual transitional theory aiming to the ideal proposal-. Once achieved the $1 \%$, with people fully compliant, we should continue for a $10 \%$ and afterwards to the moderate principle in order to end with the full compliance of Singer's strong principle. May be when fulfilling different transitional theories we do not need to achieve the ideal one (as global health may be thus achieved). But

\footnotetext{
${ }_{13}^{13}$ See http://www.thelifeyoucansave.com/home

${ }^{14}$ They argue that the basic moral code should not be far beyond the capacities of the ordinary person for otherwise there will be a general breakdown of compliance with the moral code.
} 
if this does not happen all along we still will have the stronger principle as the ideal theory to which to aim, the previous standards are the transition to it. Instead of complaining because the initial proposal has lost the power and stringency of the first principle we have now a full proposal which shows the different steps needed to get to the aim. In this sense the analysis of Singer's proposal-through the lens of ideal and non-ideal theories-turns the whole strategy meaningful. It seems my interpretation fits well with the spirit of Singer's writing. I think that this non-ideal analysis, gives more coherence to the whole proposal while providing an aim. The ideal aim still holds. And the $10 \%$ or $1 \%$ standards are clearly non-ideal.

\section{HUMAN RIGHTS FRAMEWORK: NATION STATES}

What happens with the institutional proposal? For Thomas Pogge not only citizens from the rich countries - that is, individuals - but also elites from scarce resource countries and global institutions are morally responsible for the extreme condition of the global poor. As we have seen Pogge goes further and his proposal also appeals to human rights, which is another interesting perspective worth pursuing.

Regarding the human rights framework, Article 25 of the Universal Declaration of Human Rights, Article 12 of the International Covenant on Economic, Social and Cultural Rights, the Convention on the Rights of the Child, and the Convention on the Elimination of All Forms of Discrimination Against Women - among other human rights texts - all speak of the right to enjoy the highest attainable standard of physical and mental health. This includes medical care, treatment and control of epidemic and endemic diseases, besides other issues.

Thomas Pogge generates individual duties from human rights that have governments as their primary addressees. He emphasizes the Universal Declaration's Article 28 which says that "Everyone is entitled to a social and international order in which this the rights and freedoms set forth in this Declaration can be fully realized." Pogge sees in this article a plausible norm: that both countries and individuals have negative duties not to be complicit in an international order that unfairly disadvantages poor countries and the people in them. If the international order does this, then all human agents have a negative duty, correlative to the postulated social and economic human rights, not to cooperate in upholding it unless they compensate for their cooperation by protecting its victims or by working for its reform. Those violating this duty share responsibility for the harms (insecure access to basic necessities) produced by the unjust institutional order in question" (Pogge 2002, 67).

Therefore, human rights provide an important answer. If we were to follow this path as Pogge suggests, an issue is to consider is who are relevant agents of justice. That is, while the human rights framework discourse and documents have mainly focused on the recipients, a relevant question here is who should be responsible for providing help to them? (O'Neil, 2001, p. 189). In this area, there are different analyses about the proper agents of justice. For example, "traditional" or "orthodox" interpretations hold each national state responsible for its citizens' access to health care. 
Health obligations are typically carried out by national states. States, as primary agents, should care for their people. Access to health care could be developed through public hospitals and policies and are the best suited to do so. For example, when Gostin et al.(2010) propose a Joint Learning Initiative on National and Global Responsibilities for Health, one of the proposals they outline is governments' obligations to their inhabitants and they define what these essential health services and goods are. They explain that the World Health Organization estimates an annual cost of US $\$ 40$ per person to cover these essential health services. In 2001 in Abuja, Nigeria, African heads of state pledged to devote at least 15 percent of their national budget to the health sector. Yet, in 2007, the average per capita allocation was US\$34, an average of 9.6 percent of the budget.

Can we infer that weak and poor states found this too difficult to achieve? There are at least two interpretations of this situation. The first and more benevolent one can be found in O'Neill's words: "Weak states may simply lack the resources, human, material, and organizational, to do very much to secure or improve justice within their boundaries [...] They may fail to represent the interests of their citizens adequately in international fora and may agree to damaging or unsupportable treaties or loans. They may lack the capabilities to end or prevent rebellions and forms of feudalism..." (O'Neill 2001 p. 197) This may be true of the situation of some poor states. But there can also be a second less charitable interpretation suggesting that many of these states do not carry out the necessary efforts and, regrettably, money is spent on corruption, wars, or unwise endeavors. Note that in both cases again we have partial compliance, but in these cases the states are the non-compliant agents. However the reasons are different.

At this point I propose to go back to Rawls again. His ideas may help us thinking through the challenges those different type of non-compliant states present. These states represent cases in which background institutions are not just.

If we go back to our non-compliant states we can see that the first state cannot comply due to the lack of human resources and materials. We must assess what happens and why it is not possible to comply; there might have been a climate problem, a natural catastrophe or the country is just very poor and cannot afford this kind of investment. We can think then in a transitional theory where these gaps are filled in progressively. For example by helping train efficient and motivated health workers, by helping build health systems and primary care centers, etc... This can be achieved by loans, international capacity building efforts, etc... Here again we are thinking in a transitional theory, that is a provisional and gradual theory. We can think in intermediate steps where the states resources are build (like having an efficient health care staff, etc) and then a second step reinforcing the infrastructure already achieved. And again we may still have the ideal theory as the aim. For example that the country itself be able to have and sustain an adequate health infrastructure.

The second states, instead, do have the means to comply but fails due to corruption or unwillingness to do the right thing. For this case the problem is not the lack of means but the lack of an adequate behavior on the part of elites, hence other strategies might be designed. There might be a first reaction appealing to withdraw or refuse all kind of help. However, even if the role and responsibility of these inefficient or corrupt governments is 
condemnable, the fate of the people suffering under them should be highlighted so that they are not punished even further. Giving loans or just sending money does not seem to be the right policy as there seems to be a tendency for abuse. We will need different policies such as the empowerment of citizens-instruments to hold accountable decision-makers- or national and international monitoring institutions. It may be that we need to assess the empirical and political situation of the country-for example if it is under a dictatorship or not. This case is more difficult that the first one. It involves sovereignty and very complex political and social issues. However, what is important to outline is that there might be transitional theories to work with. Policies to be designed will be quite different in one or the other case. Here Rawls three requisites seem a relevant guide as policies and courses of actions must hold to: R.1. Morally permissible; R.2. Politically possible; R.3. Likely to be effective; together with Simmon's R.4. the most grievous injustices are to be dealt with before less severe ones. Where-from an ethical perspective-the last requisite should be prior to R2 and R3. ${ }^{15}$

By using the conceptual tools just presented not only we can distinguish the cases, but we can also think in different strategies and we can justify them.

\section{INTERNATIONAL RESPONSIBILITY AND SECONDARY AGENTS}

As we have just seen, states as primary agents of justice can fail and, in fact, many of them do. Another issue to consider is the responsibility of other states as bearers of global health obligations. States vary in their ability to provide aid. The help these countries can provide can be done without suffering unreasonably high costs for their own population's quality of life and wellbeing (Lowry C and Schuklenk U, 2009). That is, global health obligations increase in proportion to the agent's capacity to assist. The more resources they have, the larger funding commitments they can achieve. Therefore, rich European countries, for example, seem to have a stronger duty to assist. Gostin et al., in exploring the responsibilities of all governments for the world's poor, also point out that high income countries have not come close to fulfilling their pledges made in 1970 to spend 0.7 percent of their gross national product per annum on Official Development Assistance. Four decades later their average contribution stands at 0.31 percent. From a human rights positive law perspective, the United Nations Charter aims at international cooperation for the solution of economic, social, cultural, or humanitarian international problems. Articles 55 and 56 explicitly establish international cooperation, among other duties to health, as "an obligation of all states". In the same vein, international, interstate or intergovernmental agencies or programs such as the World Health Organization and UNAIDS can also be held responsible. They belong to the United Nations system and were created for this and similar purposes. The constitution of the World Health Organization, for example, as the coordinating authority on international public health, states as its objective "the attainment by all people of the highest possible level of health".

\footnotetext{
${ }^{15}$ This is an interesting discussion: if there should be a priority of one requisite over the others, if the four should hold, etc. We can accept that the four should hold but that when different policies can give more weight to one or other requisite the fourth one should have priority or a prominent role.
} 
In an ideal ethical and political theory, states can be held responsible for the health of their people and richer states for international cooperation with disadvantaged countries. In an ideal theory, human rights agents are the responsible actors. This is also reflected in the international system of human rights through positive law. ${ }^{16}$ However, due to the failures of poor states and a lack of general compliance of those ideal agents (we have just pointed out the partial or lack of compliance of poor states to their citizens and the partial or noncompliance of richer states), we should think again of non-ideal strategies as a sort of bridge. These strategies, then, should focus on a combination of agents (in addition to the previous ones) working together towards global health.

For example, when discussing agents of justice, Onora O'Neill argues for a plurality of agents. She explains that primary agents (generally the national states) can construct other agents or agencies with specific competences, and they can assign powers or build institutions with certain powers and capacities to act. Secondary agents are thought to contribute to justice mainly by meeting the demands of primary agents, most evidently by conforming to any legal requirements they establish (O'Neill 2001 p. 189). O'Neill holds international non-governmental organizations and, especially, transnational or multinational companies or corporations responsible. Regarding international non-governmental organizations, she argues that their typical mission is to contribute to specific transformations of states, governments and policies - quite often to a single issue or objective. $^{17}$

In response to the question of how transnational or multinational corporations could be concerned with justice, except insofar as justice requires conformity to law, O'Neill argues that what matters is what transnational or multinational corporations or companies can or cannot do: the capabilities they can or cannot develop. ${ }^{18}$ She claims capabilities are more important than motivations: “...It is more important to consider the capabilities, rather than the (supposed) motivations of transnational companies. Many transnational companies are evidently capable of throwing their considerable weight in the direction either of greater justice, of the status quo, or of greater injustice. "Corporate power can be used to support or strengthen reasonably just states. Equally, they can accept the status quo, fall in with local elites and with patterns of injustice, and keep powers to keep things as they are - or indeed to make them more unjust." (O’Neill 2001 p. 201).

I believe these considerations regarding the capabilities of certain agents can be more defensible and stronger from a non-ideal approach than from the ideal perspective O'Neill attempts. ${ }^{19}$ What in the ideal system can be deemed as beneficent and where no strong responsibility is felt; in a non-ideal strategy other agents can also be held responsible.

\footnotetext{
16 Including interstate organizations such as the World Health Organization responsible for public health as its mission.

17 They may contribute to justice precisely because the states are too weak; they can act opportunistically and secure an unusual degree of access to some key players. O’Neill (2001) p. 199.

${ }^{18}$ She takes this concept from Amartya Sen. She says an agent's capabilities are not to be identified with their individual capacities or with their aggregate power. An agent or agency, considered in the abstract, may have various capacities or abilities to act. Capabilities are, instead, the specific capabilities of agents and agencies in specific situations rather than the abstract capacities or their aggregate power. O’Neill (2001) p. 197.

${ }^{19}$ Although I endorsed O'Neill's proposal in a previous paper, I now think that her ideas can be better defended from a nonideal perspective. Florencia Luna, "Pobreza en el mundo: obligaciones individuales, institucionales y Derechos Humanos" (2007) Revista Latinoamericana de Filosofía, vol. XXXIII, número 2, pp. 293-314.
} 
However, I believe that to hold agents responsible, we should not only consider their capabilities-as O'Neill proposes-but also two conditions more: 1) whether they are related in some relevant way to these populations and, 2) whether they can make a reasonable difference without harming or destroying themselves. In this way we do not target whatever international company-without any discrimination-but those who are relevant (are connected, work with, etc) and can be held responsible.

This is the case of major pharmaceutical companies regarding global health or of international companies based, doing research, or working substantially in these lower resource countries. Although the classic idea is that for-profit corporations obtain benefits for their stockholders, is maximizing stockholders' benefits the sole legitimate purpose of corporations? There are arguments for a stronger obligation of beneficence from a stakeholder's perspective (Freeman 1984).

In addition, we can endorse the rescue principle - a nonideal approach - to justify such obligations. Timothy Scanlon, for example, says: "If you are presented with a situation in which you can prevent something very bad from happening or alleviate someone's dire plight, by making only a slight (or even moderate) sacrifice, then it would be wrong not to do so" (Scanlon, 1998).

Although Scanlon is considering persons and reasons, this principle can easily be applied to corporations. Undoubtedly, the situation of poor countries with no or very unsatisfactory health system is so bad that providing medicines for some pharmaceutical companies is, at best, a slight sacrifice. Note that, for example, companies - especially major pharmaceutical ones - do have a policy of corporate social initiatives on which they spend millions of dollars to promote education, the sponsorship of art programs, etc.(Dunfee, 2006). Directing those funds or part of them to rescuing people from devastating preventable illnesses does not seem a sacrifice.

An additional and interesting argument is given by Thomas Dunfee (2006) regarding the role based obligation of the pharmaceutical companies. He argues for a mandatory obligation to devote substantial resources towards rescuing victims of catastrophes. He provides a stringent definition of catastrophe and points to firms that possess "unique competencies" for rescue. His position might be narrower than mine, as he attributes obligations only to very specific pharmaceutical firms due to the "uniqueness competency" criterion. However, we are both proposing a similar trend. Dunfee makes a case for some specific big pharmaceutical corporations in Sub-Saharan Africa AIDS catastrophe, but I believe his arguments are easily applicable to some of the situations depicted above.

Hence, within this framework, not only should the usual ideal agents be responsible, but transnational and pharmaceutical corporations should also be committed to the improvement of health. For example, by promoting pro-health policies through their advertising strategies, supporting local hospitals or local efforts to provide better access to health, using their resources (their fleet of trucks and logistics) to distribute medicines or other health devices, and so on. Therefore, besides wealthy countries and international organisms whose mandate 
covers these issues (such as the World Health Organizaion), from a non-ideal perspective, pharmaceutical companies and even transnational corporations can be held responsible.

\section{CONCLUSION}

We are witnesses of a global world. We are more interconnected and interdependent. There are theories and proposals that address what our obligations towards global health are. However, these proposals face strong non-compliance problems which makes them ideal or non-applicable to the real world.

In this paper I explored different non-ideal proposals: an interpretation of Singers's obligations following a non-ideal strategy; an analysis of Pogge's international human right architecture considering possible non-compliance; transitional theories in order to hold responsible national states (be them without resources to care their citizens (material impossibility) or without the relevant "will" to do it (volitional impossibility)); and finally, not only international actors as wealthy nations but also secondary agents of justice such as certain corporations or pharmaceutical companies. Non-ideal strategies turn broader the scope of responsibility and helps to solve the non-compliance challenge.

However, this does not mean we can accept whatever non ideal proposal. Not anything goes! As I have shown, another characteristic of these non-ideal proposals is to consider certain limits. In this sense the reconstruction of Rawls requisites can help. For example these nonideal strategies should be 1 . Morally permissible; 2 . Politically possible; 3 . Likely to be effective and 4. The most grievous injustices are to be dealt with before less severe ones. Thus hard theoretical and empirical work needs to be done before establishing these nonideal strategies. I only explored and sketched some possibilities.

It can also be objected that Singer and Pogge's proposals belong to different traditions and conceptual backgrounds, and this is certainly true. However, given the situation millions of people face and that both authors -even with different conceptual tools-aim to the same end (that is, to alleviate suffering and promote achieving health) we can argue that different proposals may be adopted. Moreover, both proposals focus on stressing why there are strong new obligations and not mere charity towards the distant others. It is true they choose different roads as well as different stringency and degree of commitment. But even if from different conceptual backgrounds, these proposals do not contradict or oppose each other. On the contrary, they can complement each other. For example, when Singer analyzes the role of affluent nations he says he agrees that giving privately is not enough (Singer, 1972, p. 591). Singer also states clearly that he does not want his argument to be only valid for utilitarianists, but broadly (Singer 1972, p. 594). And, in the case of Pogge, remember he not only targets states and considers human rights but also the behavior of people from wealthy countries and the elites of resource poor countries too. Hence, even if coming from different theoretical backgrounds they share a common end. Distinguishing between consequentialists and deontological positions, between Singer and Pogge can help a clear thinking as well as it can work as a didactic tool, but hanging to these distinctions may be less useful when trying to solve the current problem of global health. 
If we seriously want to address our obligations towards those in need, even if they are far away from our places we may need to work not only with ideal proposals such as the "new obligations" pointed by Singer and Pogge, but also with different transitional theories and non-ideal strategies in order to solve some of the big challenges the real world impose to theories.

\section{References}

Arneson, R. Chatterjee D The Ethics of Assistance:Morality and the Distant Needy. New York: University Press; 2004. Moral limits on the demands of beneficence?; 33-58.

Dunfee T. 2006; Do Firms with Unique Competencies for Rescuing Victims of Human Catastrophes Have Special Obligations? Corporate Responsibility and the AIDS Catastrophe in Sub-Saharan Africa. Business Ethics Quarterly. 16(2):200-202. DOI: 10.5840/beq200616222

Feinberg J, Rawls J. 1973; Duties and Obligations in the non-ideal world. The Journal of Philosophy. 70(9):263-275. DOI: 10.2307/2025007

Freeman, E. Strategic Management: A Stakehholder Approach. London: Pitman; 1984.

Goodin, R. The bioethics of Second-Best. In: Millum, J, Emanuel, E, editorsGlobal Justice and Bioethics. Oxford: Oxford University Press; 2012. 153-77.

Gostin L, Heywood M, Ooms G, Grover A, Røttingen JA, Chenguang W. 2010; National and Global Responsibilities for Health. Bulletin of the World Health Organization. 88(10):719-719A. DOI: 10.2471/BLT.10.082636 [PubMed: 20931051]

Hamlin A, Stemplowska Z. 2012; Theory, Ideal Theory and the Theory of Ideals. Political Studies Review. 10(1):48-62. DOI: 10.1111/j.1478-9302.2011.00244.x

Lowry C, Schuklenk U. 2009; Two models in Global Health Ethics. Public Health Ethics. 2(3):276284. DOI: $10.1093 / \mathrm{phe} / \mathrm{php} 032$

Millum, J, Emanuel, E. Global Justice and Bioethics. Oxford: Oxford University Press; 2012.

Murphy, L. Moral Demand in Nonideal Theory. New York: Oxford University Press; 2000.

O’Neill, O. Agents of Justice in Thomas Pogge Global Justice. Oxford: Blackwell Publishers; 2001.

Pogge T. 2001; Priorities of Global Justice. Metaphilosophy. 32(1-2):6-24. DOI: 10.1111/1467-9973.00172

Pogge, T. World Poverty and Human Rights Cosmopolitan Responsibilities and Reforms. London: Polity Press; 2002.

Pogge, T. The Role of International Law in Reproducing Massive Poverty in Besson S and Tasioulas $\mathbf{J}$ The Philosophy of International Law. Oxford: Oxford University Press; 2010. 417-436.

Rawls, J. The law of peoples. Vol. 39. Cambridge (MA): Harvard University Press; 1999. 69Section 2

Scanlon, T. What we Owe to Each Other. Cambridge: The Belknap Press of Harvard University Press; 1998. 224

Simmons J. 2010; Ideal and NonidealTheory. Philosophy \& Public Affairs. 38(1):5-36. DOI: 10.1111/j.1088-4963.2009.01172.x

Simmons J. 2010; Ideal and Nonideal Theory. Philosophy \& Public Affairs. 38(1):5-36. DOI: 10.1111/j.1088-4963.2009.01172.x

Singer P. 1972; Famine, affluence and morality. Philosophy and Public Affairs. 1(3):229243.Reprinted inLaFollette, H. An Anthology. Cambridge, Massachussets: Blackwell; 1997. Ethics in Practice; 585-595. 586In this paper I will quote LaFollette's edition

Sreenivasan, G. Nonideal Theory: A Taxonomy with illustration. In: Millum, J, Emanuel, E, editorsGlobal Justice and Bioethics. Oxford: Oxford University Press; 2012. 153-177. 